ARTICLE

https://doi.org/10.1038/s41467-019-09409-1

\title{
Coulombic self-ordering upon charging a large- capacity layered cathode material for rechargeable batteries
}

Benoit Mortemard de Boisse ${ }^{1}$, Marine Reynaud ${ }^{2}$, Jiangtao Ma¹, Jun Kikkawa ${ }^{3}$, Shin-ichi Nishimura (1) 1,4, Montse Casas-Cabanas², Claude Delmas ${ }^{5}$, Masashi Okubo ${ }^{1,4}$ \& Atsuo Yamada (D) 1,4

Lithium- and sodium-rich layered transition-metal oxides have recently been attracting significant interest because of their large capacity achieved by additional oxygen-redox reactions. However, layered transition-metal oxides exhibit structural degradation such as cation migration, layer exfoliation or cracks upon deep charge, which is a major obstacle to achieve higher energy-density batteries. Here we demonstrate a self-repairing phenomenon of stacking faults upon desodiation from an oxygen-redox layered oxide $\mathrm{Na}_{2} \mathrm{RuO}_{3}$, realizing much better reversibility of the electrode reaction. The phase transformations upon charging $\mathrm{A}_{2} \mathrm{MO}_{3}$ ( $\mathrm{A}$ : alkali metal) can be dominated by three-dimensional Coulombic attractive interactions driven by the existence of ordered alkali-metal vacancies, leading to counterintuitive self-repairing of stacking faults and progressive ordering upon charging. The cooperatively ordered vacancy in lithium-/sodium-rich layered transition-metal oxides is shown to play an essential role, not only in generating the electro-active nonbonding $2 p$ orbital of neighbouring oxygen but also in stabilizing the phase transformation for highly reversible oxygen-redox reactions.

\footnotetext{
${ }^{1}$ Department of Chemical System Engineering, School of Engineering, The University of Tokyo, Hongo 7-3-1, Bunkyo-ku, Tokyo 113-8656, Japan. ${ }^{2} \mathrm{CIC}$ energiGUNE, Parque Tecnológico de Álava, 01510 Vitoria-Gasteiz, Álava, Spain. ${ }^{3}$ Advanced Key Technologies Division, National Institute for Materials Science, Tsukuba, Ibaraki 305-0044, Japan. ${ }^{4}$ Elements Strategy Initiative for Catalysts \& Batteries (ESICB), Kyoto University, Nishikyo-ku, Kyoto 614-8245, Japan. ${ }^{5}$ Institut de Chimie de la Matière Condensée de Bordeaux (ICMCB), 33600 Pessac, France. Correspondence and requests for materials should be addressed to A.Y. (email: yamada@chemsys.t.u-tokyo.ac.jp)
} 
T he discovery of intercalation chemistry in layered transition-metal oxides $\mathrm{AMO}_{2}(\mathrm{~A}=\mathrm{Li}, \mathrm{Na}$ and $\mathrm{M}=$ transition metal $)^{1,2}$ in the early 1980 s has led to the commercialization of lithium-ion batteries ${ }^{3}$. Tremendous effort has since been devoted to understanding how alkali-metal ions reversibly (de)intercalate in $\mathrm{AMO}_{2}$ because this is essential to exploit their large theoretical capacities $\left(\sim 275 \mathrm{mAh} \mathrm{g}^{-1}\right.$ for $\mathrm{LiCoO}_{2}$ and $\sim 235$ $\mathrm{mAh} \mathrm{g}^{-1}$ for $\mathrm{NaCoO}_{2}$, respectively). It is now well understood that, at the early stage of $\mathrm{A}^{+}$deintercalation, $\mathrm{A}_{x} \mathrm{MO}_{2}(0.4<x<$ 1.0) exhibit an increase of their interlayer distance because the depletion of screening $\mathrm{A}^{+}$layers enhances the effective Coulombic repulsion between oxide ions of adjacent $\mathrm{MO}_{2}$ layers ${ }^{4-8}$. At the late stage of $A^{+}$deintercalation $(0.0<x<0.4)$, high-valent $\mathrm{M}$ increases the covalency of $\mathrm{M}-\mathrm{O}$ bonds, and thus decreases the negative charge on oxide ions. In this situation, $\mathrm{O}-\mathrm{O}$ van der Waals attraction forces are not sufficient to maintain the layered structure, and the large volume variations induced at the end of charge often initiate crack formation and delamination/exfoliation $^{8-10}$. Furthermore, the lack of alkali ions in the interlayer space leads to structural degradation with migration of transitionmetal ions to neighboring tetrahedral sites ${ }^{11-13}$. This established knowledge on the intercalation chemistry of $\mathrm{A}_{x} \mathrm{MO}_{2}$ explains the practical limit of their reversible capacity (approximately for 0.4 $<x<1.0$, i.e., $170 \mathrm{mAh} \mathrm{g}^{-1}$ for $\mathrm{A}=\mathrm{Li}$ and $140 \mathrm{mAh} \mathrm{g}^{-1}$ for $\mathrm{A}=$ $\mathrm{Na}$ ). Therefore, the control of the competing Coulombic and van der Waals forces in layered transition-metal oxides is of great importance to achieve a large reversible capacity.
Layered $A$-excess transition-metal oxides $\left(\mathrm{A}_{1+y} \mathrm{M}_{1-y} \mathrm{O}_{2}\right.$ or $\left.\mathrm{A}_{1}\left[\mathrm{~A}_{y} \mathrm{M}_{1-y}\right] \mathrm{O}_{2}\right)$ are recent major targets to increase the cathode capacity by virtue of additional oxygen-redox reactions. $\mathrm{Li}_{2} \mathrm{MnO}_{3}-\mathrm{LiMO}_{2}$ solid solutions have been reported to deliver large capacities over $200 \mathrm{mAh} \mathrm{g}^{-114-16}$, and have more recently been followed by $\mathrm{Li}_{2} \mathrm{MO}_{3}\left(\mathrm{M}=\mathrm{Ru}^{17}, \mathrm{Ir}^{18}, \mathrm{RuSn}^{17}\right.$, and $\left.\mathrm{RuMn}^{19}\right)$ and $\mathrm{Na}_{2} \mathrm{MO}_{3}\left(\mathrm{M}=\mathrm{Ru}^{20,21}, \mathrm{RuSn}^{21}\right.$, and $\left.\mathrm{Ir}^{22}\right)$, all delivering large capacities exceeding that of solely $\mathrm{M}$ redox. Although the changes in the electronic state during the additional oxygen-redox reactions have been intensively investigated, less attention has been paid to the essential interaction dominating the phase transformation during the charge/discharge processes, presumably because most oxygen-redox electrodes exhibit severe structural degradation (i.e., oxygen-gas evolution, cation migration) at the initial charge $16,17,23,24$. However, the extra $\mathrm{A}^{+}$are expected to play a crucial role in the structural transformation during the charge/discharge processes. For example, the depletion of screening $\mathrm{A}^{+}$layers upon charging can be compensated by the $\mathrm{A}^{+}$supplied from the $\left[\mathrm{A}_{y} \mathrm{M}_{1-y}\right] \mathrm{O}_{2}$ layers ${ }^{18,20,22}$. Moreover, $\mathrm{A}^{+}$ (or vacancy after deintercalation) in the $\left[\mathrm{A}_{y} \mathrm{M}_{1-y}\right] \mathrm{O}_{2}$ layers is expected to modulate the balance of competing Coulombic/van der Waals forces, and hence largely influence the intercalation chemistry.

We have recently studied the structure and electrochemistry of O3- $\mathrm{Na}_{2} \mathrm{RuO}_{3}$ (or $\mathrm{Na}\left[\mathrm{Na}_{1 / 3} \mathrm{Ru}_{2 / 3}\right] \mathrm{O}_{2}$ ), where $\left[\mathrm{Na}_{1 / 3} \mathrm{Ru}_{2 / 3}\right] \mathrm{O}_{2}$ layers have a honeycomb-type ordered arrangement of $\mathrm{Na}$ and $\mathrm{Ru}^{20,25}$. According to the classification of layered oxides, O3 denotes a structure where $\mathrm{Na}^{+}$ions occupy octahedral interlayer sites and
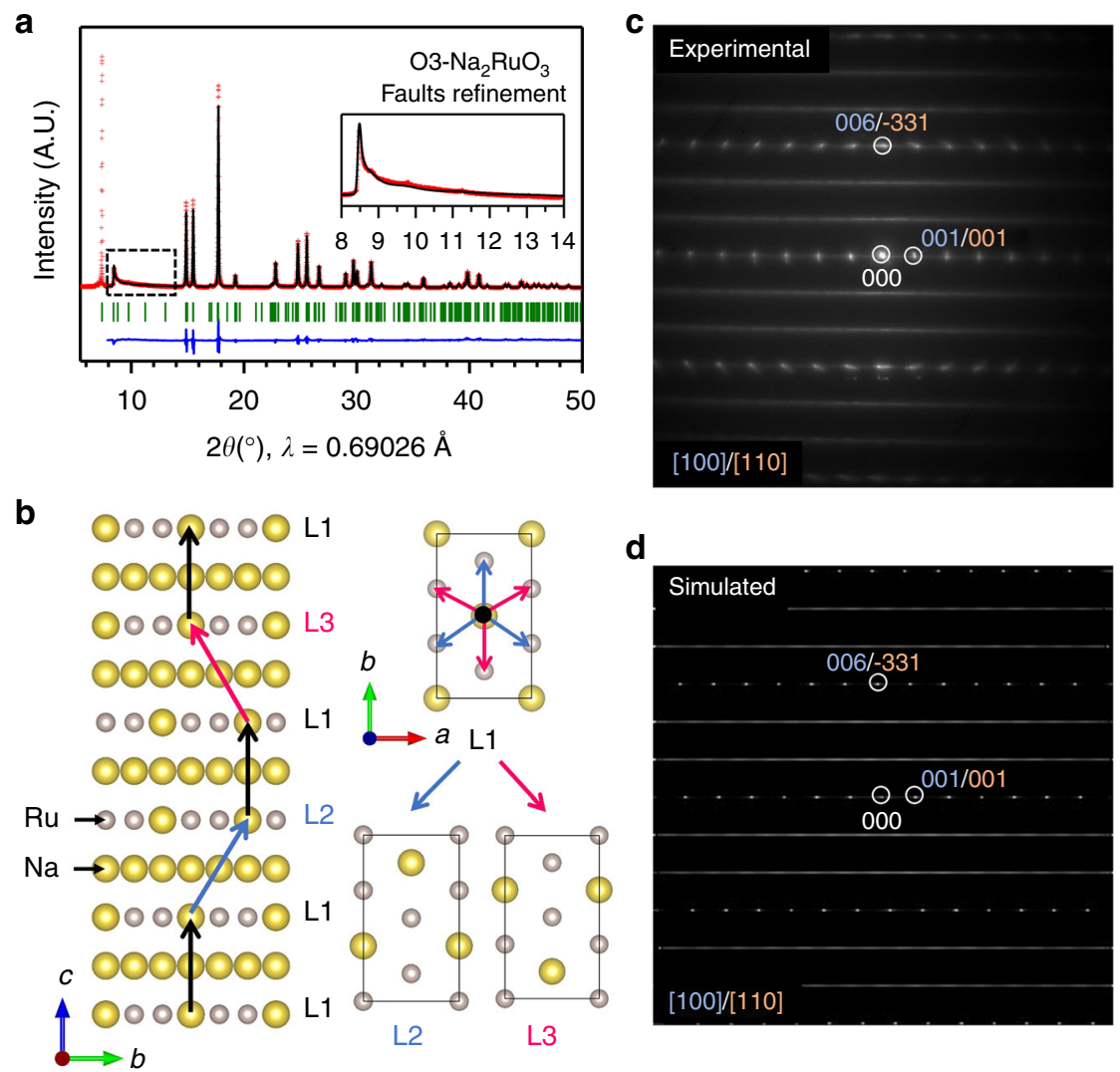

Fig. 1 Stacking faults in $\mathrm{Na}_{2} \mathrm{RuO}_{3}$. a Observed and calculated (FAULTS refinement) synchrotron XRD patterns of O3-Na $\mathrm{RuO}_{3}$ (pristine state). Observed data, the calculated pattern, and the difference between observed and calculated data are shown as plus sign (red), solid line (black) and continuous line (blue), respectively. The positions of Bragg reflections are indicated by vertical tick marks (green). The first diffraction peak has been excluded from the refinement due to important asymmetry that FAULTS does not take into account. The insert is a zoom of the initial superstructure peaks (Warren fall). b Representation of the stacking faults in $\mathrm{O} 3-\mathrm{Na}_{2} \mathrm{RuO}_{3}$, using the FAULTS unit cell described in the text. c, $\mathbf{d}$ Experimental and simulated SAED pattern along the $[100]\left(=<[110]_{C 2 / m}>\right)$ direction, respectively 
the stacking of oxide ions is $\mathrm{ABCABC}$ (Supplementary Fig. 1) ${ }^{26}$. Importantly, in contrast to most oxygen-redox electrodes, O3$\mathrm{Na}_{2} \mathrm{RuO}_{3}$ exhibits highly reversible (de)sodiation without structural degradation but rather exhibits progressive structural ordering upon charging, which provides an opportunity for not only detailed structural investigation as a model system but also for essential strategies toward much larger reversible capacity.

In this work, synchrotron X-ray diffraction coupled with planar-defect refinement analyses are applied to honeycomb ordered $\mathrm{Na}_{x} \mathrm{RuO}_{3}$ phases $(x=2,1$, and $1 / 2)$, revealing a selfrepairing phenomenon of stacking faults upon charging, which significantly stabilizes the reversible large capacity operation. Driving force of the 3D self-ordering is strong long-range cooperative Coulombic interactions between $\mathrm{MO}_{3}$ slabs intermediated by ordered vacancies.

\section{Results}

Stacking faults in $\mathrm{Na}_{2} \mathrm{RuO}_{3}$. O3- $\mathrm{Na}_{2} \mathrm{RuO}_{3}$ was synthesized by decomposing $\mathrm{Na}_{2} \mathrm{RuO}_{4}$ at $850^{\circ} \mathrm{C}$ for $12 \mathrm{~h}$ under $\mathrm{Ar}$ atmosphere ${ }^{20,25}$. Figure 1a shows the experimental and calculated synchrotron XRD patterns of O3- $\mathrm{Na}_{2} \mathrm{RuO}_{3}$, in which the most of intense diffraction peaks can be fitted by the usual rhombohedral lattice of $\mathrm{O} 3-\mathrm{AMO}_{2}$ layered oxides ${ }^{20}$. However, the main difficulty hindering an accurate pattern fit lies in the broad nature of some diffraction peaks and diffuse scatterings, which are

a
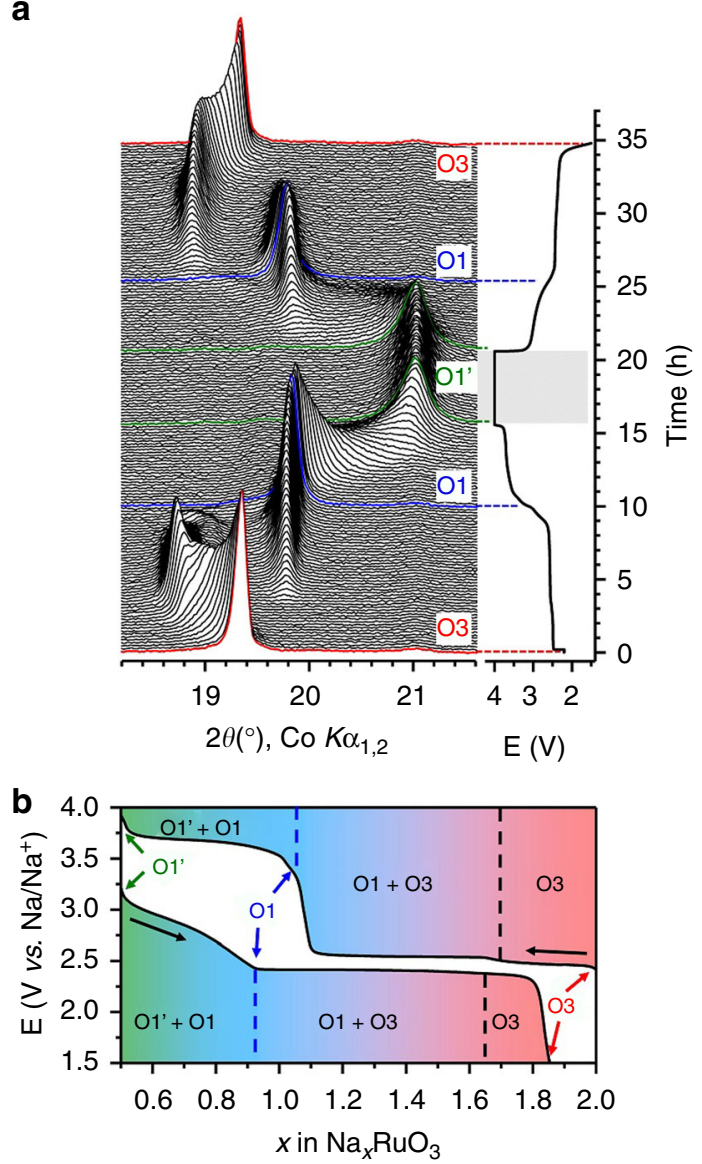

Fig. 2 Structural evolution upon charging/discharging $\mathrm{Na}_{2} \mathrm{RuO}_{3}$. a XRD patterns recorded in situ during the first cycle of $\mathrm{Na}_{2} \mathrm{RuO}_{3}$ with the corresponding cycling curve. The dashed area corresponds to a potentiostatic break whose aim was to ensure the equilibrium state at $4.0 \mathrm{~V}$ before discharging the cell. $\mathbf{b}$ Phase diagram as determined from the in situ experiment as a function of the sodium content highlighted by the dashed rectangle in Fig. 1a. Such broadening is typically observed for $\mathrm{A}_{2} \mathrm{MO}_{3}$ with honeycomb ordered $\left[\mathrm{A}_{1 / 3} \mathrm{M}_{21}\right.$ ${ }_{3} \mathrm{O}_{2}$ layers, and arises from stacking disorder. These stacking faults can be described by an occasional shift of the $\left[\mathrm{A}_{1 / 3} \mathrm{M}_{2 / 3}\right] \mathrm{O}_{2}$ layers perpendicularly to the stacking direction. In fact, in layered materials, the crystal grows perpendicularly to the layer plane. When a nucleation starts in a wrong position, a stacking fault appears while the oxygen packing remains ideal. As a result, the honeycomb ordering of the $\left[\mathrm{A}_{1 / 3} \mathrm{M}_{2 / 3}\right] \mathrm{O}_{2}$ layers is maintained but the honeycomb stacking deviates from the ideal sequence (Fig. 1b), which causes the peculiar asymmetric peak broadening (Warren fall) observed in Fig. 1a as well as the diffuse streaks on the selected area electron diffraction (SAED) pattern along the $[100]-<110>_{C 2 / m}$ direction (Fig. 1c).

To refine the powder diffraction data for the structure containing stacking faults, a FAULTS analysis, which allows the incorporation of the occurrence probabilities of possible stackings, was conducted ${ }^{27}$. As shown in Fig. 1a (Supplementary Tables 1 and 2), the FAULTS analysis provides a satisfactory
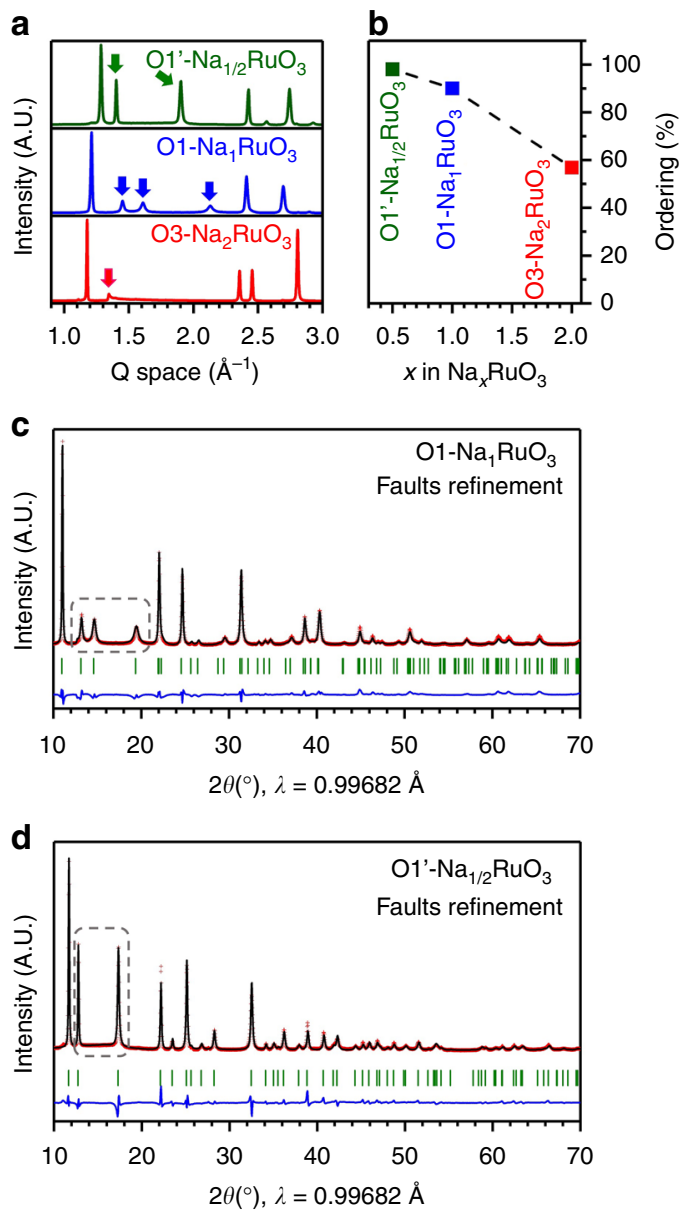

Fig. 3 Progressive stacking-fault-depression (self-ordering) upon charging $\mathrm{Na}_{2} \mathrm{RuO}_{3}$. a Synchrotron XRD patterns of O3- $\mathrm{Na}_{2} \mathrm{RuO}_{3}, \mathrm{O} 1-\mathrm{Na}_{1} \mathrm{RuO}_{3}$ and $\mathrm{O}^{\prime}-\mathrm{Na}_{1 / 2} \mathrm{RuO}_{3}$. Arrows indicate the most intense superstructure peaks. b Evolution of the ordered stacking (absence of stacking faults) as a function of the $\mathrm{Na}$ content. The error bars are smaller than the mark size. c, d Observed and calculated (FAULTS refinement) synchrotron XRD patterns of $\mathrm{O} 1-\mathrm{Na}_{1} \mathrm{RuO}_{3}$ and $\mathrm{O1}^{\prime}-\mathrm{Na}_{1 / 2} \mathrm{RuO}_{3}$, respectively. Red crosses: experimental, black line: calculated, blue line: difference plot and green bars: Bragg positions in the $\mathrm{R} \overline{3}: \mathrm{h}$ and $\mathrm{P} \overline{3} 1 \mathrm{~m}$ space groups for $\mathrm{O} 1-\mathrm{Na}_{1} \mathrm{RuO}_{3}$ and $\mathrm{O}^{\prime}-\mathrm{Na}_{1 / 2} \mathrm{RuO}_{3}$, respectively. The dashed rectangles indicate the most intense superstructure peaks 
description of the superstructure peaks and indicates the occurrence of $\sim 40 \%$ stacking faults between the $\left[\mathrm{Na}_{1 / 3} \mathrm{Ru}_{2 / 3}\right] \mathrm{O}_{2}$ layers in pristine $\mathrm{O} 3-\mathrm{Na}_{2} \mathrm{RuO}_{3}$. This result is further supported by the FAULTS-simulated SAED pattern that well reproduces the diffuse streaks observed in the experimental SAED pattern (Fig. 1d).

After evaluation of the stacking faults in pristine $\mathrm{O} 3-\mathrm{Na}_{2} \mathrm{RuO}_{3}$, we studied the structural evolution of $\mathrm{Na}_{x} \mathrm{RuO}_{3}$ during the first charge and discharge using in situ XRD. Figure 2 shows that the phase transformation of $\mathrm{Na}_{x} \mathrm{RuO}_{3}$ involves three main phases: O3- $\mathrm{Na}_{x} \mathrm{RuO}_{3}, \mathrm{O} 1-\mathrm{Na}_{1} \mathrm{RuO}_{3}$, and $\mathrm{Ol}^{\prime}-\mathrm{Na}_{1 / 2} \mathrm{RuO}_{3}$. (De)sodiation at $2.7 \mathrm{~V}$ vs. $\mathrm{Na} / \mathrm{Na}^{+}(1.0<x<2.0)$ mainly proceeds through a twophase process between $\mathrm{O} 3-\mathrm{Na}_{x} \mathrm{RuO}_{3}$ and $\mathrm{O} 1-\mathrm{Na}_{1} \mathrm{RuO}_{3}$. As reported previously, $\mathrm{O} 1-\mathrm{Na}_{1} \mathrm{RuO}_{3}$ has an ilmenite-type structure (ABAB oxide-ions stacking and $\mathrm{Na}^{+}$ions in interlayer octahedral sites) where the honeycomb ordered $\left[\mathrm{Ru}_{2 / 3} \square_{1 / 3}\right] \mathrm{O}_{2}$ and $\left[\mathrm{Na}_{2 /}\right.$ $\left.{ }_{3} \square_{1 / 3}\right]_{\mathrm{O}_{2}}$ layers ( $\square: \mathrm{Na}^{+}$vacancy) stack alternatively (Supplementary Fig. 2) ${ }^{20}$. At the second charging plateau, a new phase $\left(\mathrm{O}^{\prime}-\mathrm{Na}_{1 / 2} \mathrm{RuO}_{3}\right)$ with a shorter interlayer distance $(4.91 \AA$ vs. $5.21 \AA$ for $\mathrm{O} 1-\mathrm{Na}_{1} \mathrm{RuO}_{3}$ ) appears at the expense of the O1 phase. Its structure was determined from the synchrotron XRD pattern of an electrochemically deintercalated sample, whose Rietveld refinement is presented in Supplementary Fig. 3 and Supplementary Table 3. The diffraction peaks are successfully indexed in a hexagonal lattice with $P \overline{3} 1 \mathrm{~m}$ symmetry with $a=5.1876(9) \AA$ and $c=4.906(1) \AA$. As the oxide-ion stacking sequence is $\mathrm{ABAB}$ and
$\mathrm{Na}^{+}$occupies an octahedral site, we will refer to this phase as $\mathrm{Ol}^{\prime}-\mathrm{Na}_{1 / 2} \mathrm{RuO}_{3}$, where the alternate stacking of the honeycomb ordered [ $\left[\mathrm{Ru}_{2 / 3} \square_{1 / 3}\right] \mathrm{O}_{2}$ and $\left[\mathrm{Na}_{1 / 3} \square_{2 / 3}\right] \mathrm{O}_{2}$ layers is maintained. Then, the difference between the $\mathrm{O} 1$ and $\mathrm{O}^{\prime}$ structures lies in the $\mathrm{Na}$ content and on the respective stacking of the $\left[\mathrm{Ru}_{2 / 3} \square_{1 / 3}\right] \mathrm{O}_{2}$ layers, which are shifted from one another in $\mathrm{O} 1-\mathrm{Na}_{1} \mathrm{RuO}_{3}$ while directly stacked in $\mathrm{Ol}^{\prime}-\mathrm{Na}_{1 / 2} \mathrm{RuO}_{3}$ (Supplementary Figs. 2 and 3). It is noteworthy that the superstructure peaks highlighted by the arrows in Fig. 3a exhibit remarkable sharpening upon charging. This suggests that stacking faults tend to disappear, assisted by the adjustable layer gliding involved in the $\mathrm{O} 3 \rightarrow \mathrm{O}^{\prime}$ transition. The FAULTS refinements (Fig. 3c, d and Supplementary Tables 4-6) indicate that the occurrence probability of stacking faults indeed decreases from $40 \%$ in $\mathrm{O} 3-\mathrm{Na}_{2} \mathrm{RuO}_{3}$ to $10 \%$ (O1$\left.\mathrm{Na}_{1} \mathrm{RuO}_{3}\right)$ and then to $2 \%\left(\mathrm{Ol}^{\prime}-\mathrm{Na}_{1 / 2} \mathrm{RuO}_{3}\right)$ (Fig. 3b). Therefore, $\mathrm{Na}^{+}$deintercalation (charging) from $\mathrm{Na}_{2} \mathrm{RuO}_{3}$ involves a selfreorganization process that significantly diminishes the initial amount of stacking faults. Importantly, the stacking faults are reformed after discharging, making this ordering/faulting process reversible, even after several cycles (Supplementary Figs. 4 and 5).

Self-ordering of stacking faults upon charging $\mathrm{Na}_{2} \mathrm{RuO}_{3}$. Based on the complete knowledge of the structural evolution from $\mathrm{O}_{3}$ $\mathrm{Na}_{2} \mathrm{RuO}_{3}$ to $\mathrm{O} 1-\mathrm{Na}_{1} \mathrm{RuO}_{3}$, and then to $\mathrm{O}^{\prime}-\mathrm{Na}_{1 / 2} \mathrm{RuO}_{3}$, let us now consider the Coulombic origin of the consolidation on the phase transformation with the effect of gliding vectors $t \rightarrow$ of the

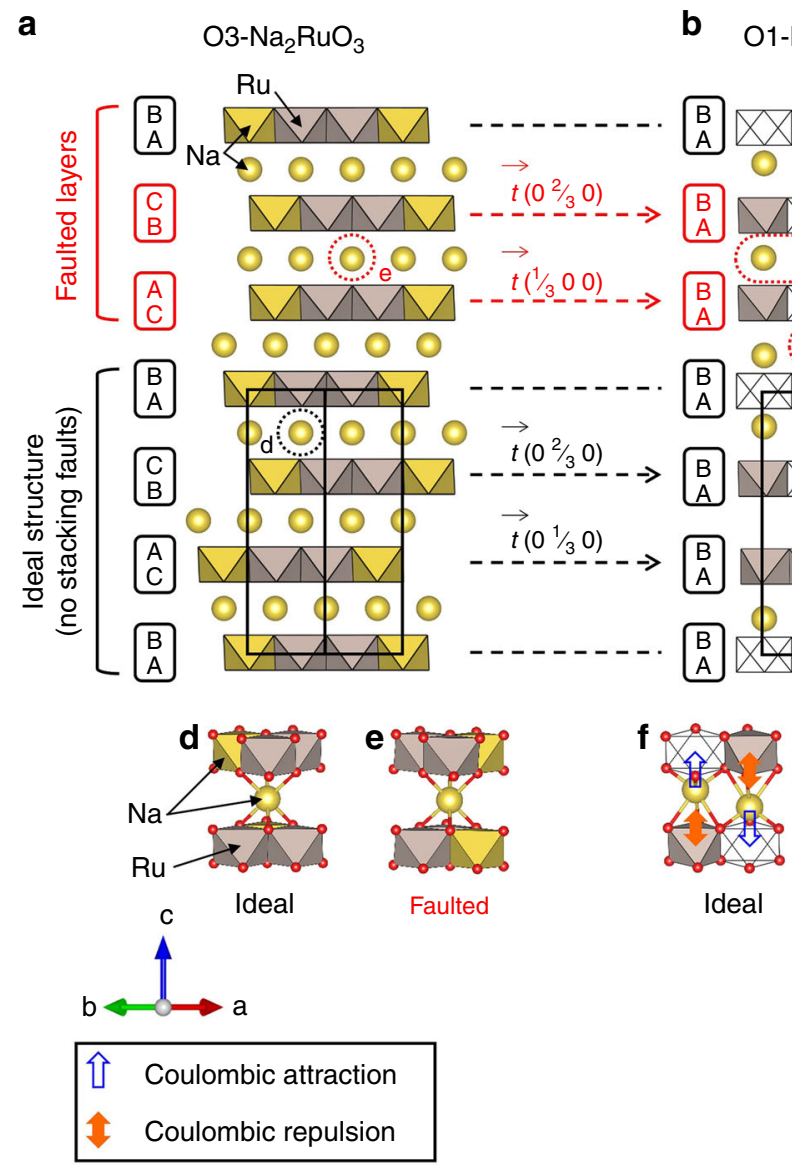

O1- $-\mathrm{Na}_{1} \mathrm{RuO}_{3} \quad$ C ${ }^{\prime}-\mathrm{Na}_{1 / 2} \mathrm{RuO}_{3}$

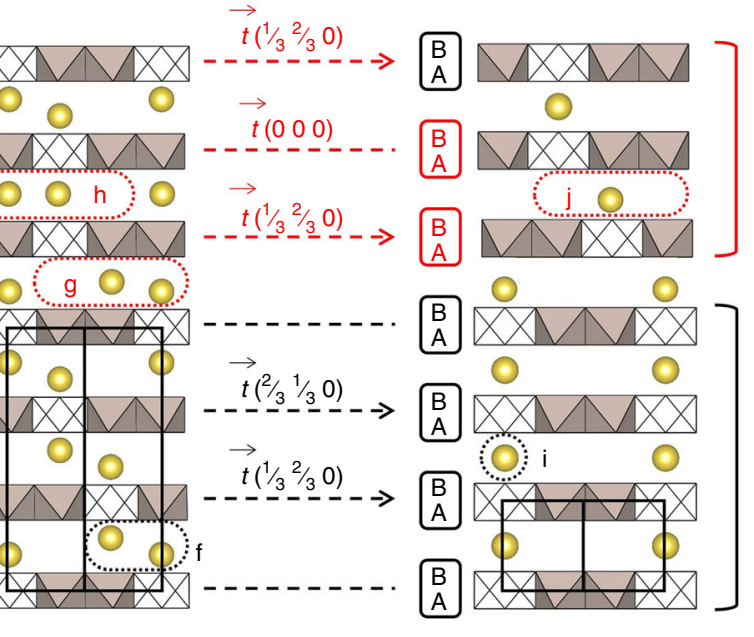

Fig. 4 Coulombic forces and resultant stacking-fault-depression (self-ordering) in $\mathrm{Na}_{2-x} \mathrm{RuO}_{3}$. Structural representation and projected stacking sequences of the Ru atoms of $\mathbf{a} \mathrm{O} 3-\mathrm{Na}_{2} \mathrm{RuO}_{3}, \mathbf{b}$ O1- $\mathrm{Na}_{1} \mathrm{RuO}_{3}$ and $\mathbf{c} \mathrm{O}^{\prime}-\mathrm{Na}_{1 / 2} \mathrm{RuO}_{3}$. The monoclinic cell of O3-Na $\mathrm{RuO}_{3}$ has been converted to a pseudo-hexagonal supercell (black lines) for comparison. The transition vectors in the hexagonal supercell from one $\left[\mathrm{Ru}_{2 / 3} \mathrm{Na}_{1 / 3}\right]_{2}$ or $\left[\mathrm{Ru}_{2 / 3} \square 1 / 3 \mathrm{O}_{2}\right]$ layer to another are indicated with respect to the pseudo-hexagonal or hexagonal cells. Note that the transition vectors assigned to faulted layers are a few examples out of many possibilities listed in Supplementary Figs. 5 and 6. d-j Comparison of the $\mathrm{Na}$ environments in ideal and faulted stacking highlighted with dashed circles in the structures shown in a-c 
a

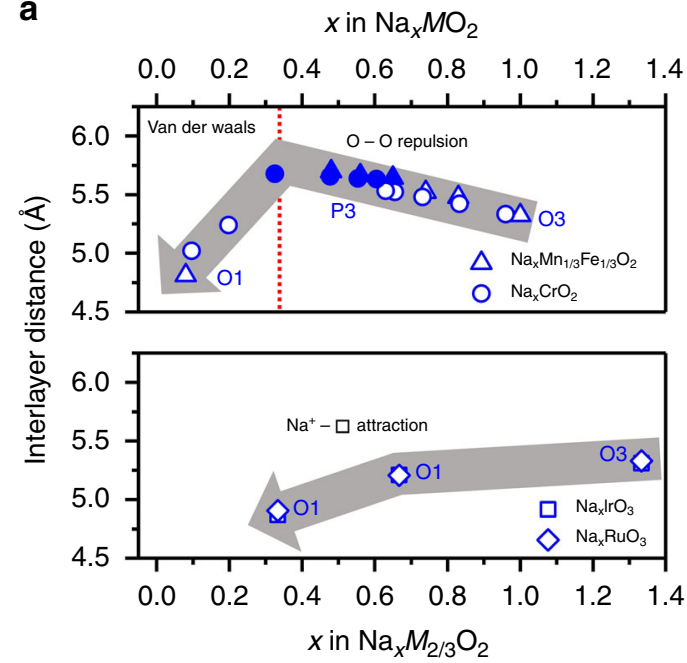

b

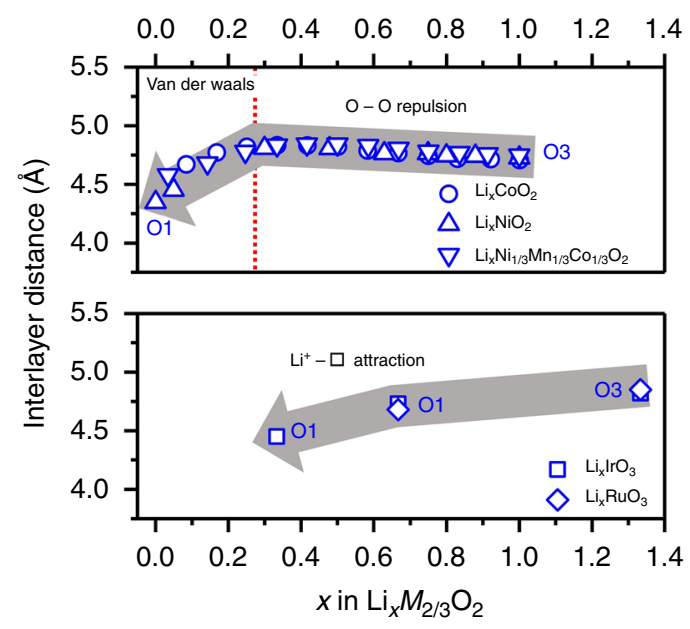

Fig. 5 Overviewing dominant forces for phase transformation during $\mathrm{A}^{+}$ de-intercalation from $\mathrm{AMO}_{2}$ and $\mathrm{A}_{2} \mathrm{MO}_{3}$. Comparison of the general trends in interlayer distance evolution between a $\mathrm{Na}_{x} \mathrm{MO}_{2}\left(\mathrm{M}=\mathrm{Cr}^{28}\right.$ and $\left.\mathrm{Fe}_{2 / 3} \mathrm{Mn}_{1 / 3}{ }^{8}\right)$ and $\mathrm{Na}_{2} \mathrm{MO}_{3}\left(\mathrm{M}=\mathrm{Ru}\right.$ (this study) and $\mathrm{Ir}^{22}$ ) and $\mathbf{b} \mathrm{Li}_{x} \mathrm{MO}_{2}$ $\left(\mathrm{M}=\mathrm{Co}^{4}, \mathrm{Ni}^{6}\right.$ and $\left.\mathrm{Ni}_{1 / 3} \mathrm{Mn}_{1 / 3} \mathrm{Co}_{1 / 3}{ }^{7}\right)$ and $\mathrm{Li}_{x} \mathrm{MO}_{3}\left(\mathrm{M}=\mathrm{Ru}^{17}\right.$ and $\left.\mathrm{Ir}^{18}\right)$

$\left[\mathrm{Ru}_{2 / 3} \mathrm{Na}_{1 / 3}\right] \mathrm{O}_{2}$ (or $\left[\mathrm{Ru}_{2 / 3} \square_{1 / 3}\right] \mathrm{O}_{2}$ ) layers (Fig. $4 \mathrm{a}-\mathrm{c}$ ). Note that the vectors are given in the pseudo-hexagonal cell $\left(\mathrm{O}_{3}-\mathrm{Na}_{2} \mathrm{RuO}_{3}\right)$ or in the hexagonal cells $\left(\mathrm{O} 1-\mathrm{Na}_{1} \mathrm{RuO}_{3}\right.$ and $\mathrm{O}^{\prime}-\mathrm{Na}_{1 / 2} \mathrm{RuO}_{3}$; Supplementary Table 7). In O3- $\mathrm{Na}_{2} \mathrm{RuO}_{3}$ (Fig. 4a), the $\mathrm{NaO}_{6}$ octahedron in $\mathrm{Na}$ layers shares edges with two $\mathrm{NaO}_{6}$ and four $\mathrm{RuO}_{6}$ octahedra in the adjacent $\left[\mathrm{Ru}_{2 / 3} \mathrm{Na}_{1 / 3}\right] \mathrm{O}_{2}$ layers (Fig. $4 \mathrm{~d}$ ). As the stacking faults only impact the stacking of the $\left[\mathrm{Ru}_{2 / 3} \mathrm{Na}_{1 / 3}\right]$ $\mathrm{O}_{2}$ layers, the $\mathrm{Na}^{+}$ions in the $\mathrm{Na}$ layer have the same local environment (Fig. 4e) and it can be considered that a different stacking is equally probable in $\mathrm{O}_{3}-\mathrm{Na}_{2} \mathrm{RuO}_{3}$. However, in O1$\mathrm{Na}_{1} \mathrm{RuO}_{3}$ consisting of honeycomb ordered $\left[\mathrm{Ru}_{2 / 3} \square_{1 / 3}\right] \mathrm{O}_{2}$ and $\left[\mathrm{Na}_{2 / 3} \square_{1 / 3}\right] \mathrm{O}_{2}$ layers with the ABAB oxygen packing (Fig. $4 \mathrm{~b}$ ), all the octahedral positions in the slab share faces with the octahedral positions of the interslab space (Supplementary Fig. 6). As a result, the gliding vectors $t \rightarrow$ that shift each layer of $\mathrm{O} 3-\mathrm{Na}_{2} \mathrm{RuO}_{3}$ to the ones of O1- $\mathrm{Na}_{1} \mathrm{RuO}_{3}$ are ideally adjusted to set each $\mathrm{NaO}_{6}$ octahedron in the $\left[\mathrm{Na}_{2 / 3} \square_{1 / 3}\right]$ layers to share faces with a $\square \mathrm{O}_{6}$ octahedron and a $\mathrm{RuO}_{6}$ octahedron in the adjacent $\left[\mathrm{Ru}_{2 / 3} \square_{1 / 3}\right]$ $\mathrm{O}_{2}$ layers (Fig. 4f and Supplementary Fig. 7). The stronger attraction of the oxygen atoms surrounding a vacancy on the $\mathrm{Na}^{+}$ ion (later referred to as $\mathrm{Na}^{+}-\square$ Coulombic attraction for simplicity) and the $\mathrm{Na}^{+}-\mathrm{Ru}^{5+}$ Coulombic repulsion cooperatively displace the $\mathrm{Na}^{+}$ion toward $\square^{20}$. When assuming the hypothetical stacking faults (Fig. $4 \mathrm{~g}, \mathrm{~h}$ ), one of two $\mathrm{NaO}_{6}$ octahedra is trapped between two $\mathrm{RuO}_{6}$ octahedra, where strong $\mathrm{Ru}^{5+}-\mathrm{Na}^{+}$ $-\mathrm{Ru}^{5+}$ Coulombic repulsions make the faulted structural option unfavorable. Consequently, during the $\mathrm{O} 3$ to $\mathrm{O} 1$ transformation, slab gliding tends to occur in a way which minimizes the Coulombic energy and as a consequence removes the stacking faults, as described in Fig. 4 and Supplementary Fig. 7. Owing to the three-directional gliding possibilities, most of the stacking faults disappear during the transformation. However, the $\mathrm{NaO}_{6}$ octahedron can occasionally be stabilized by the local $\square-\mathrm{Na}^{+}-\square$ Coulombic attraction (Fig. 4h), and some stacking faults may remain in $\mathrm{O} 1-\mathrm{Na}_{1} \mathrm{RuO}_{3}$.

On the other hand, in $\mathrm{Ol}^{\prime}-\mathrm{Na}_{1 / 2} \mathrm{RuO}_{3}$ (Fig. $4 \mathrm{c}$ and Supplementary Fig. 3b), which consists of honeycomb ordered alternating $\left[\mathrm{Ru}_{2 / 3} \square_{1 / 3}\right] \mathrm{O}_{2}$ and $\left[\mathrm{Na}_{1 / 3} \square_{2 / 3}\right]$ layers, the $\mathrm{NaO}_{6}$ octahedron shares faces with two $\square \mathrm{O}_{6}$ octahedra in the adjacent $\left[\mathrm{Ru}_{2 / 3} \square_{1 / 3}\right] \mathrm{O}_{2}$ layers (Fig. 4c, i). Again with hypothetical stacking faults resulting from $t \rightarrow$ different from the ideal ones shown in Supplementary Fig. 8, the $\mathrm{NaO}_{6}$ octahedron in the $\left[\mathrm{Na}_{1 / 3} \square_{2 / 3}\right]$ layer shares faces with $\square \mathrm{O}_{6}$ and $\mathrm{RuO}_{6}$ octahedra, and the local $\mathrm{Na}^{+}-\mathrm{Ru}^{5+}$ Coulombic repulsion prohibits the formation of the faulted structure (Fig. 4j). Therefore, the amount of the stacking faults in $\mathrm{Na}_{x} \mathrm{RuO}_{3}(1 / 2 \leq x \leq 2)$ continuously diminishes as desodiation proceeds, because the ordered stacking sequences become electrostatically more favorable. As discussed above, no peculiar local environment is stabilized in $\mathrm{O} 3-\mathrm{Na}_{2} \mathrm{RuO}_{3}$, which allows for stacking faults reformation upon sodiation (Supplementary Figs. 4 and 5).

\section{Discussion}

The aforementioned importance of the attractive $\mathrm{A}^{+}-\square$ and repulsive $\mathrm{A}^{+}-\mathrm{M}^{5+}$ Coulombic interactions can lead to more general discussions on the phase stability of $\mathrm{A}_{2} \mathrm{MO}_{3}$ and $\mathrm{AMO}_{2}$ upon charging. Figure $5 \mathrm{a}$ shows the experimental evolution of the interlayer distance upon charging various $\mathrm{Na}_{x} \mathrm{MO}_{2}(\mathrm{M}=3 \mathrm{~d})^{8,28}$ and $\mathrm{Na}_{2} \mathrm{MO}_{3}(\mathrm{M}=4 \mathrm{~d}, 5 \mathrm{~d})^{22}$ compounds as a function of the sodium content. Figure $5 \mathrm{~b}$ shows the similar plots for the lithium analogs, $\mathrm{LiMO}_{2}$ and $\mathrm{Li}_{2} \mathrm{MO}_{3} 4,6,7,17,18$. It is noteworthy that all $\mathrm{AMO}_{2}(\mathrm{~A}=\mathrm{Li}, \mathrm{Na}$ and $\mathrm{M}=3 \mathrm{~d})$ and all $\mathrm{A}_{2} \mathrm{MO}_{3}(\mathrm{~A}=\mathrm{Li}, \mathrm{Na}$ and $\mathrm{M}=4 \mathrm{~d}, 5 \mathrm{~d}$ ) respectively follow the same tendencies.

As mentioned in the introduction, the phase transformation of $A_{x} \mathrm{MO}_{2}$ is dominated by the competing $\mathrm{O}-\mathrm{O}$ Coulombic repulsion $(0.4<x<1.0)$ and van der Waals attraction $(0<x<0.4)$ between adjacent $\mathrm{MO}_{2}$ layers ${ }^{4-8}$, which initiates the increase of the interlayer distance $(0.4<x<1.0)$ followed by its abrupt decrease upon deeper charging $(0<x<0.4)$. Structural evolution in the "Coulombic domain" with large $\mathrm{A}^{+}$content $(0.4<x<1.0)$ are highly reversible and is the basis of commercial positive electrode materials such as $\mathrm{LiCoO}_{2}$ and $\mathrm{Li}\left[\mathrm{Ni}_{1-y-z} \mathrm{Mn}_{y} \mathrm{Co}_{z}\right] \mathrm{O}_{2}$, while the "van der Waals domain" with smaller $\mathrm{A}^{+}$content $(0<x$ $<0.4)$ marks the limit of reversibility of many practical layered oxides as a result of cation migration, spinel transformation, crack formation, and delamination/exfoliation ${ }^{8-13}$.

On the contrary, the highly ordered nature of the $\left[\mathrm{Ru}_{2 / 3} \square_{1 / 3}\right]$ $\mathrm{O}_{2}$ layers of $\mathrm{A}_{x} \mathrm{MO}_{3}(\mathrm{M}=\mathrm{Ru}$ or Ir) triggers a progressive gain in $\mathrm{A}^{+}-\square$ Coulombic energy upon $\mathrm{A}^{+}$extraction as the remaining $\mathrm{A}^{+}$ions cooperatively act as robust pillars between adjacent $\left[\mathrm{Ru}_{2 /}\right.$ $\left.{ }_{3} \square_{1 / 3}\right] \mathrm{O}_{2}$ layers to prevent structural collapse. The slight decrease of the interlayer distance is driven by Coulombic $\mathrm{A}^{+}-\square$ attractive forces which are strong enough to induce the slab glidings, $\mathrm{O} 3 \rightarrow \mathrm{O} 1 \rightarrow \mathrm{Ol}^{\prime}$, forming a more-ordered structure upon charging. It is this situation that realizes reversible 
charge-discharge reactions in ordered $\mathrm{A}_{2} \mathrm{MO}_{3}$ over a wide compositional domain of the guest ion $\mathrm{A}^{+}$.

In summary, we identified a spontaneous reorganization of the stacking faults in $\mathrm{Na}_{x} \mathrm{RuO}_{3}$, a model material to understand oxygen-redox reactions in layered oxides for large-capacity battery electrodes. In particular, the progressive ordering upon charging process is a general phenomenon to $\mathrm{A}_{2} \mathrm{MO}_{3}(\mathrm{~A}=\mathrm{Li}, \mathrm{Na}$ and $M=4 d, 5 d)$ materials and is induced by the cooperative effect of maximizing the $\mathrm{A}^{+}-\square$ Coulombic attraction and minimizing the $\mathrm{A}^{+}-\mathrm{M}^{5+}$ Coulombic repulsion, which significantly enlarges the reversible operation range of layered oxides. Complementarily to our previous work, in addition to generate redox-active "orphaned" nonbonding oxygen $2 p$ orbitals to "activate" additional oxygen-redox reactions, honeycomb ordering of $\mathrm{M}$ and $\square$ contribute to "stabilizing" reversible phase transformation. In this regard, the importance of the overall material design that includes ordered vacancies with its neutral charge to attract alkali cations was highlighted. By establishing proper ways to control the stacking faults ${ }^{29-31}$ or vacancies $^{32}$, the concept of progressive ordering upon charging may be extended to stabilize other related compounds ${ }^{33}$.

\section{Methods}

Synthesis of $\mathbf{N a}_{\mathbf{2}} \mathbf{R} \mathbf{u} \mathbf{O}_{\mathbf{3}} . \mathrm{Na}_{2} \mathrm{RuO}_{3}$ was prepared according to the literature ${ }^{25}$. First, $\mathrm{Na}_{2} \mathrm{RuO}_{4}$ is prepared by mixing stoichiometric amounts of $\mathrm{Na}_{2} \mathrm{O}_{2}$ (Sigma-Aldrich) and $\mathrm{RuO}_{2}$ (Kanto chemicals). Pellets are then made and introduced in a tubular furnace to be annealed at $650{ }^{\circ} \mathrm{C}$ for $12 \mathrm{~h}$ under $\mathrm{O}_{2}$ atmosphere. After the synthesis, $\mathrm{Na}_{2} \mathrm{RuO}_{4}$ is grinded and shaped into pellets again to be thermally decomposed into $\mathrm{Na}_{2} \mathrm{RuO}_{3}$ at $850^{\circ} \mathrm{C}$ for $12 \mathrm{~h}$ under Ar atmosphere. After cooling down to room temperature, the sample is introduced in an Ar filled glovebox.

Characterization. The synchrotron XRD patterns were recorded at Aichi Synchrotron Radiation Center (Aichi-SR, O3- $\mathrm{Na}_{2} \mathrm{RuO}_{3}$ ), and Photon Factory at High Energy Accelerator Research organization (KEK-PF, BL-8B) or SPring-8 (O1$\mathrm{Na}_{1} \mathrm{RuO}_{3}$ and $\mathrm{Ol}^{\prime}-\mathrm{Na}_{1 / 2} \mathrm{RuO}_{3}$, beamline 02B2). All samples were protected from air exposure during the measurement. Rietveld refinement was performed using Jana2006 ${ }^{34}$. Analyses of the stacking faults in the materials were carried out using the FAULTS software ${ }^{27}$. The crystal structures were drawn using VESTA ${ }^{35}$. Selected Area Electron Diffraction (SAED) patterns were recorded using an electron microscope (HF-3000S; Hitachi Ltd. and Titan Cubed; FEI Co.) operated at $300 \mathrm{kV}$. The camera length for SAED was calibrated with a Si crystal.

Electrochemistry. Electrochemical measurements were carried out in $\mathrm{Na}_{2} \mathrm{RuO}_{3} /$ electrolyte/Na half-cells assembled in CR2032 type coin cells. The electrolyte was 1 $\mathrm{mol} / \mathrm{L} \mathrm{NaPF}_{6}$ in EC:DEC (1:1) purchased from Chameleon Reagent. Positive electrodes were prepared by coating a slurry made of active material ( $80 \mathrm{wt} \%$ ) mixed with acetylene black (10 wt\%) and polyvinylidene (10 wt\%) in NMP onto Al foil. Sixteen-mm-diameter electrodes were cut after drying for one night under vacuum at $120^{\circ} \mathrm{C}$. The positive and negative electrodes were separated by a layer of Whatman glass fiber separator soaked with electrolyte. The galvanostatic curve was recorded and controlled using a TOSCAT-3100 battery tester. The charge/discharge rate was $\mathrm{C} / 10$ which corresponds to the (de)intercalation of $1 \mathrm{Na}^{+}$per $\mathrm{Na}_{\mathrm{x}} \mathrm{RuO}_{3}$ in 10 hours. The $\mathrm{O} 1-\mathrm{Na}_{1} \mathrm{RuO}_{3}$ and $\mathrm{O} 1^{\prime}-\mathrm{Na}_{1 / 2} \mathrm{RuO}_{3}$ samples were prepared by cycling sintered pellets (diameter $10 \mathrm{~mm}$, weight $\approx 10-15 \mathrm{mg}$ ) of O3$\mathrm{Na}_{2} \mathrm{RuO}_{3}$ at $\mathrm{C} / 50$ (one $\mathrm{Na}^{+}$exchanged in $50 \mathrm{~h}$ ) until a given voltage $(3.07 \mathrm{~V}$ and $4.0 \mathrm{~V}$ vs. $\mathrm{Na} / \mathrm{Na}^{+}$for $\mathrm{O} 1-\mathrm{Na}_{1} \mathrm{RuO}_{3}$ and $\mathrm{Ol}^{\prime}-\mathrm{Na}_{1 / 2} \mathrm{RuO}_{3}$, respectively). The recovered materials were then washed 3 to 5 times with dimethyl carbonate in the glovebox before sending to the synchrotron facility.

In situ X-ray diffraction. In situ XRD was carried out in operando using an in situ cell purchased from Bruker on a Bruker-AXS D8 ADVANCE (Co Ka radiation) in $0.02^{\circ}$ steps over the $2 \theta$ range of $17-25^{\circ}$ at a $C / 10$ rate. The cell configuration is similar to the one described above except for the positive electrode that consisted in a mixture of $\mathrm{Na}_{2} \mathrm{RuO}_{3}$ ( $85 \mathrm{wt} \%$ ), acetylene black (10 wt\%), and polytetrafluoroethylene $(5 \mathrm{wt} \%)$. Two layers of glass fiber separators were used to prevent dendrite formation.

\section{Data availability}

The whole datasets are available from the corresponding author on request.

Received: 21 February 2019 Accepted: 12 March 2019

Published online: 16 May 2019

\section{References}

1. Mizushima, K., Jones, P. C., Wiseman, P. J. \& Goodenough, J. B. $\mathrm{Li}_{x} \mathrm{CoO}_{2}(0<$ $\mathrm{x}<1$ ): a new cathode material for batteries of high energy density. Mater. Res. Bull. 15, 783-789 (1980).

2. Delmas, C., Braconnier, J.-J., Fouassier, C. \& Hagenmuller, P. Electrochemical intercalation of sodium in $\mathrm{Na}_{x} \mathrm{CoO}_{2}$ bronzes. Solid State Ion. 3-4, 165-169 (1981).

3. Yoshino, A. The birth of the lithium-ion battery. Angew. Chem. Int. Ed. 51, 5798-5800 (2012).

4. Laubach, S. et al. Changes in the crystal and electronic structure of $\mathrm{LiCoO}_{2}$ and $\mathrm{LiNiO}_{2}$ upon $\mathrm{Li}$ intercalation and deintercalation. Phys. Chem. Chem. Phys. 11, 3278-3289 (2009).

5. Li, W., Reimers, J. N. \& Dahn, J. R. In situ X-ray diffraction and electrochemical studies of $\mathrm{Li}_{1-x} \mathrm{NiO}_{2}$. Solid State Ion. 67, 123-130 (1993).

6. Pouillerie, C., Croguennec, L. \& Delmas, C. The $\mathrm{Li}_{x} \mathrm{Ni}_{1-y} \mathrm{Mg}_{y} \mathrm{O}_{2}(y=0.05$, $0.10)$ system: structural modifications observed upon cycling. Solid State Ion. 132, 15-29 (2000)

7. Yabuuchi, N., Makimura, Y. \& Ohzuku, T. Solid-state chemistry and electrochemistry of $\mathrm{LiCo}_{1 / 3} \mathrm{Ni}_{1 / 3} \mathrm{Mn}_{1 / 3} \mathrm{O}_{2}$ for advanced lithium-ion batteries III. Rechargeable capacity and cycleability. J. Electrochem. Soc. 154, A314-A321 (2007).

8. Mortemard de Boisse, B. et al. O3- $\mathrm{Na}_{x} \mathrm{Mn}_{1 / 3} \mathrm{Fe}_{2 / 3} \mathrm{O}_{2}$ as a positive electrode material for $\mathrm{Na}$-ion batteries: structural evolutions and redox mechanisms upon $\mathrm{Na}^{+}$(de)intercalation. J. Mater. Chem. A 3, 10976-10989 (2015).

9. Chen-Wiegart, Y.-cK., Liu, Z., Faber, K. T., Barnett, S. A. \& Wang, J. 3D analysis of a $\mathrm{LiCoO}_{2}-\mathrm{Li}\left(\mathrm{Ni}_{1 / 3} \mathrm{Mn}_{1 / 3} \mathrm{Co}_{1 / 3}\right) \mathrm{O}_{2} \mathrm{Li}$-ion battery positive electrode using x-ray nano-tomography. Electrochem. Commun. 28, 127-130 (2013).

10. Basch, A., de Campo, L., Albering, J. H. \& White, J. W. Chemical delithiation and exfoliation of $\mathrm{Li}_{x} \mathrm{CoO}_{2}$. J. Solid State Chem. 220, 102-110 (2014).

11. Rougier, A., Gravereau, P. \& Delmas, C. Optimization of the composition of the $\mathrm{Li}_{1-z} \mathrm{Ni}_{1+z} \mathrm{O}_{2}$ electrode materials: structural, magnetic, and electrochemical studies. J. Electrochem. Soc. 143, 1168-1175 (1996).

12. Kim, S., Ma, X., Ong, S. P. \& Ceder, G. A comparison of destabilization mechanisms of the layered $\mathrm{Na}_{x} \mathrm{MO}_{2}$ and $\mathrm{Li}_{\mathrm{X}} \mathrm{MO}_{2}$ compounds upon alkali deintercalation. Phys. Chem. Chem. Phys. 14, 15571-15578 (2012).

13. Choi, S. \& Manthiram, A. Factors influencing the layered to spinel-like phase transition in layered oxide cathodes. J. Electrochem. Soc. 149, A1157-A1163 (2002).

14. Lu, Z., Beaulieu, L. Y., Donaberger, R. A., Thomas, C. L. \& Dahn, J. R. Synthesis, structure, and electrochemical behavior of $\mathrm{Li}\left[\mathrm{Ni}_{x} \mathrm{Li}_{1 / 3-2 x / 3} \mathrm{Mn}_{2 / 3-x / 3}\right]$ $\mathrm{O}_{2}$. J. Electrochem. Soc. 149, A778-A791 (2002).

15. Koga, H. et al. Reversible oxygen participation to the redox processes revealed for $\mathrm{Li}_{1.20} \mathrm{Mn}_{0.54} \mathrm{Co}_{0.13} \mathrm{Ni}_{0.13} \mathrm{O}_{2}$. J. Electrochem. Soc. 160, A786-A792 (2013).

16. Koga, H. et al. Different oxygen redox participation for bulk and surface: a possible global explanation for the cycling mechanism of $\mathrm{Li}_{1,20} \mathrm{Mn}_{0.54} \mathrm{Co}_{0.13} \mathrm{Ni}_{0.13} \mathrm{O}_{2}$. J. Power Sources 236, 250-258 (2013).

17. Sathiya, M. et al. Reversible anionic redox chemistry in high-capacity layeredoxide electrodes. Nat. Mater. 12, 827-835 (2013).

18. McCalla, E. et al. Visualization of O-O peroxo-like dimers in high-capacity layered oxides for Li-ion batteries. Science 350, 1516-1521 (2015).

19. Sathiya, $\mathrm{M}$. et al. High performance $\mathrm{Li}_{2} \mathrm{Ru}_{1-y} \mathrm{Mn}_{y} \mathrm{O}_{3}(0.2<\mathrm{y}<0.8)$ cathode materials for rechargeable lithium-ion batteries: their understanding. Chem. Mater. 25, 1121-1131 (2013).

20. Mortemard de Boisse, B. et al. Intermediate honeycomb ordering to trigger oxygen redox chemistry in layered battery electrode. Nat. Commun. 7, 11397 (2016).

21. Rozier, P. et al. Anionic redox chemistry in Na-rich $\mathrm{Na}_{2} \mathrm{Ru}_{1-y} \mathrm{Sn}_{y} \mathrm{O}_{3}$ positive electrode material for Na-ion batteries. Electrochem. Commun. 53, 29-32 (2015).

22. Perez, A. J. et al. Strong oxygen participation in the redox governing the structural and electrochemical properties of Na-rich layered oxide $\mathrm{Na}_{2} \mathrm{IrO}_{3}$. Chem. Mater. 28, 8278-8288 (2016)

23. Luo, K. et al. Charge-compensation in $3 d$-transition-metal-oxide intercalation cathodes through the generation of localized electron holes on oxygen. Nat. Chem. 8, 684-691 (2016).

24. Sathiya, M. et al. Origin of voltage decay in high-capacity layered oxide electrodes. Nat. Mater. 14, 230-238 (2015).

25. Mogare, K. M., Friese, K., Klein, W. \& Jansen, M. Syntheses and crystal structures of two sodium ruthenates: $\mathrm{Na}_{2} \mathrm{RuO}_{4}$ and $\mathrm{Na}_{2} \mathrm{RuO}_{3}$. Z. Anorg. Allg. Chem. 630, 547-552 (2004).

26. Delmas, C., Fouassier, C. \& Hagenmuller, P. Structural classification and properties of the layered oxides. Physica 99, 81-85 (1980).

27. Casas-Cabanas, M., Reynaud, M., Rikarte, J., Horbach, P. \& RodriguezCarvajal, J. FAULTS: a program for refinement of structures with extended defects. J. Appl. Cryst. 49, 2259-2269 (2016). 
28. Kubota, K. et al. New insight into structural evolution in layered $\mathrm{NaCrO}_{2}$ during electrochemical sodium extraction. J. Phys. Chem. C 119, 166-175 (2015).

29. Boulineau, A., Croguennec, L., Delmas, C. \& Weill, F. Structure of $\mathrm{Li}_{2} \mathrm{MnO}_{3}$ with different degrees of defects. Solid State Ion. 180, 1652-1659 (2010).

30. Kobayashi, H., Tabuchi, M., Shikano, M., Kageyama, H. \& Kanno, R. Structure, and magnetic and electrochemical properties of layered oxides, $\mathrm{Li}_{2} \mathrm{IrO}_{3}$. J. Mater. Chem. 13, 957-962 (2003).

31. Serrano-Sevillano, J. et al. Enhanced electrochemical performance of Li-rich cathode materials through microstructural control. Phys. Chem. Chem. Phys. 20, 23112-23122 (2018).

32. Mortemard de Boisse, B. et al. Highly reversible oxygen-redox chemistry at 4.1 $\mathrm{V}$ in $\mathrm{Na}_{4 / 7-x}\left[\square_{1 / 7} \mathrm{Mn}_{6 / 7}\right] \mathrm{O}_{2}$ ( $\square$ : Mn vacancy). Adv. Energy Mater. 8, 180409 (2018).

33. Assadi, M. H. N., Okubo, M., Yamada, A. \& Tateyama, Y. Oxygen redox in hexagonal layered $\mathrm{Na}_{x} \mathrm{TMO}_{3}(\mathrm{TM}=4 \mathrm{~d}$ elements) for high capacity $\mathrm{Na}$ ion batteries. J. Mater. Chem. A 6, 3747-3753 (2018).

34. Petricek, V., Dusek, M. \& Palatinus, L. Crystallographic computing system JANA2006: general features. Z. Krist. 229, 345-352 (2014).

35. Momma, K. \& Izumi, F. VESTA 3 for three-dimensional visualization of crystal, volumetric and morphology data. J. Appl. Cryst. 44, 1272-1276 (2011).

\section{Acknowledgements}

This work was supported by a JSPS Grant-in-Aid for Specially Promoted Research (No. 15H05701). This work was also financially supported by the Ministry of Education,

Culture, Sports, Science and Technology (MEXT), Japan under the "Elemental Strategy Initiative for Catalysts and Batteries (ESICB)". M.O. was supported by JSPS KAKENHI Grant Number JP18K19124. The synchrotron powder diffraction experiment for structure analyses were performed at BL5S2 of Aichi-SR (Proposal No. 2017D3004,

2017D3010, and 2017D4010), BL-8B of KEK-PF (Proposal No. 2015G684) and BL02B2 of SPring-8 (2015A1503). B.M.B. acknowledges the Japan Society for the Promotion of Science for his JSPS fellowship. M.R. acknowledges the support of the Spanish Ministerio de Economía y Competitividad (MINECO) through her research fellowship (reference number FJCI-2014-19990). M.R. and M.C.C. thank MINECO for financial support (reference numbers: ENE2016-81020-R and ENE2016-75242-R).

\section{Author contributions}

B.M.B., M.O., and A.Y. conceived and directed the project. B.M.B. and J.M. synthesized $\mathrm{Na}_{2} \mathrm{RuO}_{3}$. B.M.B. characterized $\mathrm{Na}_{2} \mathrm{RuO}_{3}$. J.K. measured SAED patterns. S.N. conducted synchrotron X-ray diffraction experiments. B.M.B., M.R., and M.C.C. conducted FAULT analysis. B.M.B. and C.D. analyzed the phase transformations. All authors wrote the manuscript.

\section{Additional information}

Supplementary Information accompanies this paper at https://doi.org/10.1038/s41467019-09409-1.

Competing interests: The authors declare no competing interests.

Reprints and permission information is available online at http://npg.nature.com/ reprintsandpermissions/

Journal peer review information: Nature Communications thanks the anonymous reviewer(s) for their contribution to the peer review of this work.

Publisher's note: Springer Nature remains neutral with regard to jurisdictional claims in published maps and institutional affiliations.

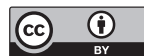

Open Access This article is licensed under a Creative Commons Attribution 4.0 International License, which permits use, sharing, adaptation, distribution and reproduction in any medium or format, as long as you give appropriate credit to the original author(s) and the source, provide a link to the Creative Commons license, and indicate if changes were made. The images or other third party material in this article are included in the article's Creative Commons license, unless indicated otherwise in a credit line to the material. If material is not included in the article's Creative Commons license and your intended use is not permitted by statutory regulation or exceeds the permitted use, you will need to obtain permission directly from the copyright holder. To view a copy of this license, visit http://creativecommons.org/ licenses/by/4.0/.

(C) The Author(s) 2019 